\title{
A redenção cósmica do mestiço: inversão semântica do conceito de raça na Raza cósmica de José Vasconcelos
}

The cosmic redemption of the "mestizo": semantic inversion of the concept of race in José Vasconcelos' Cosmic race

João Gabriel da Silva Ascenso

\section{Jesus e Coatlicue}

Em 1746, o sacerdote mexicano Andrés Arce y Miranda escreveu a Juan José de Eguiara y Eguren - professor e reitor da Universidade do México - uma carta em que manifestava sua forte preocupação com o argumento que circulava no cenário europeu de que os literatos criollos não tinham "sangue puro". Isto

João Gabriel da Silva Ascenso é mestrando em História Social no Instituto de Filosofia e Ciências Sociais da UFRJ, Rio de Janeiro, Brasil, e bolsista do CNPq. É editor executivo da Revista de la Associación Latinoamericana de Archivos (jgascenso@ig.com.br).

Artigo recebido em 30 de junho e aprovado para publicação em 4 de setembro de 2013. 


\section{A redenção cósmica do mestiço}

contribuía, segundo ele, para a indiferença da Europa em relação aos escritos e trabalhos dos membros da elite colonial. Na carta, Arce y Miranda condenava o próprio uso do termo criollo para definir os descendentes de espanhóis nascidos na América, por acreditar que ele lhes conferia certa feição "mesclada". Por "denigrativo e infamatório", portanto, o termo deveria ser substituído por "espanhóis americanos".

O sacerdote destacava que o erro a ser combatido se devia a certas pinturas retratando diversas "castas" americanas que estavam sendo enviadas à Espanha, que associariam a imagem do continente à "mescla de sangues". Arce y Miranda aludia à iniciativa do vice-rei Fernando de Alencastre Noroña y Silva, duque de Linares, de presentear o rei da Espanha com uma série de pinturas do célebre pintor barroco Juan Rodríguez Juarez, retratando as misturas de sangue possíveis entre os habitantes do Novo Mundo. Mencionava, ainda, que Juan Francisco de Loaiza, bispo auxiliar de Puebla, teria tido a mesma ideia, encomendando a Luis Berrueco uma tela dividida em 16 painéis, em cada um dos quais haveria uma cena com três pessoas - pai, mãe e filho - ordenadas a partir da procedência dos pais (espanhola, indígena, negra, ou combinações desses elementos). ${ }^{1}$

Essa carta é a primeira referência registrada a respeito do gênero artístico conhecido como "pintura de castas", que experimentou grande desenvolvimento no vice-reino da Nova Espanha durante o século XVIII. As pinturas geralmente representavam 16 combinações possíveis entre as linhagens sanguíneas "espanhola", "índia" e "negra", dispondo os tipos humanos resultantes dessas misturas em diferentes castas, ordenadas numericamente. Na Imagem 1, podemos observar uma dessas pinturas, de autor desconhecido e que se encontra atualmente no Museo Nacional del Virreinato, no México.

Ironicamente, $\mathrm{o}$ interesse em produzir as pinturas de castas não diferia muito daquele de Arce y Miranda ao criticá-las. Nos dois casos, verificamos o objetivo central de afirmar a ordem social da colônia e a pureza sanguínea dos "espanhóis americanos".

Como podemos perceber na Imagem 1 , a ordenação das castas parece indicar o status mais elevado dos grupos menos "mesclados", os primeiros a serem retratados na pintura. Além disso, a própria classificação sugere uma hierarquia sólida na organização social local, baseada na desigualdade do sangue. De forma significativa, percebemos a ausência de referência quanto à procedência do tipo branco, descrito apenas como "español": o fato de criollos e peninsulares serem representados em pé de igualdade nos indica o interesse da elite colonial em se ver reconhecida como igual pelos espanhóis peninsulares, e como diferente dos tipos "de sangue impuro" - cuja classificação se desdobra de maneira complexa ao longo das gerações. 
João Gabriel da Silva Ascenso

\section{Imagem 1 - Castas}

Reprodução autorizada pelo Instituto Nacional de Antropología e Historia, 2013.

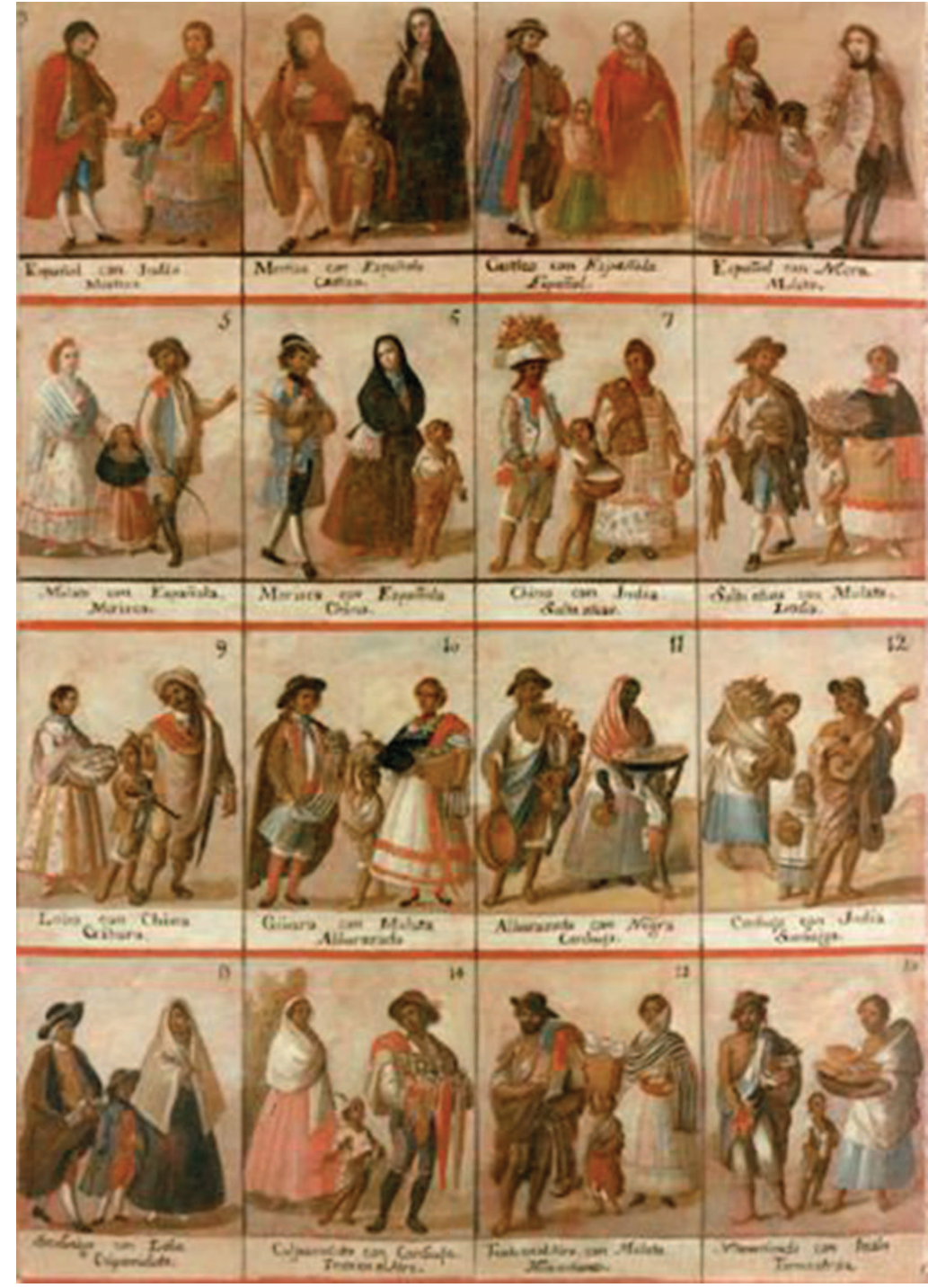

Legenda:

1.Español con India, Mestizo; 2.Mestizo con Española, Castizo; 3.Castiza con Español, Española; 4.Español con Negra, Mulato; 5.Mulato con Española, Morisca; 6.Morisco con Española, Chino; 7.Chino con India, Salta atrás; 8.Salta atrás con Mulata, Lobo; 9.Lobo con China, Gíbaro; 10.Gíbaro con Mulata, Albarazado; 11.Albarazado con Negra, Cambujo; 12.Cambujo con India, Sambiaga; 13. Sambiago con Loba, Calpamulato; 14.Calpamulato con Cambuja, Tente en el aire; 15. Tente en el aire con Mulata, No te entiendo; 16. No te entiendo con India, Torna atrás. 


\section{A redenção cósmica do mestiço}

De todo modo, mais do que uma ação visando à afirmação de um grupo social, enviar tais pinturas à Coroa Espanhola significava reafirmar que havia ordem na colônia, que a sociedade ainda se assentava sobre bases hierárquicas rígidas, em um momento de crescente perda de controle que foi o século XVIII. Isso não se deveu apenas à crescente complexificação das “misturas sanguíneas", mas ao fato de que o aumento da interação entre as castas, através, inclusive, de casamentos entre grupos diferentes, fazia com que as fronteiras sociais se tornassem cada vez mais fluidas, bem como o acesso à riqueza, levando a uma crescente inquietação por parte da elite branca da colônia.

O surgimento das pinturas de castas se relaciona ao desejo de definição do papel dos atores na sociedade colonial, visando também a uma legitimação da posição de destaque dos criollos - ou espanhóis americanos - frente aos espanhóis peninsulares. Arce y Miranda, por outro lado, defendia que tais pinturas divulgavam para a Europa "las mentes útiles pero no las nobles", "lo que nos daña, no lo que nos aprovecha, lo que nos infama, no lo que nos ennoblece" (Arce y Miranda apud Morales, 1983), refletindo, de certa maneira, a mesma preocupação fundamental com a regulamentação e a manutenção das diferenças quanto aos tipos humanos presentes na colônia espanhola na América, ainda que discordando radicalmente da solução adotada: ao invés de divulgar uma diversidade sob controle, o certo seria escondê-la.

$* * *$

Mais de um século e meio depois da carta indignada do sacerdote ao seu amigo literato, já na segunda década do século XX, um jovem pintor mexicano chamado Saturnino Herrán, atendendo à convocatória do diretor da Academia de San Carlos, concebeu o projeto vencedor do friso a ser pintado na decoração do Teatro Nacional do México (hoje Palácio de Belas Artes). Entre 1915 e 1916, Herrán trabalhou na concepção daquele que se tornaria o trabalho mais ambicioso de sua vida, o tríptico conhecido como Nuestros Dioses.

O projeto da obra impressiona pela riqueza de significados que se espalham pelas três partes que a compõem e, sobretudo, pela expressividade de sua imagem central, batizada Coatlicue Transformada. Nela, nos deparamos com a austera e imponente divindade asteca Coatlicue - a mãe da terra e dos deuses - representada como uma mulher com duas cabeças de serpente a se mirarem, com garras nas mãos e nos pés, carregando um colar de corações, mãos e crânios humanos e vestindo uma saia de serpentes contorcidas. Incrustada em seu peito, encontra-se a figura crucificada de Jesus Cristo, coroado com uma auréola luminosa e ainda sangrando. No painel esquerdo, índios se ajoelham perante a divindade mista, carregando frutas em oferenda e prestando reverência. No direito, conquistadores e sacerdotes espanhóis também cultuam o Jesus feito parte de Coatlicue, prostrando-se e portando uma imagem da Virgem Maria em procissão. 


\section{João Gabriel da Silva Ascenso}

Imagem 2 - Nuestros Dioses, Saturnino Herrán

Reprodução autorizada pelo Instituto Nacional de Bellas Artes y Literatura, 2013.
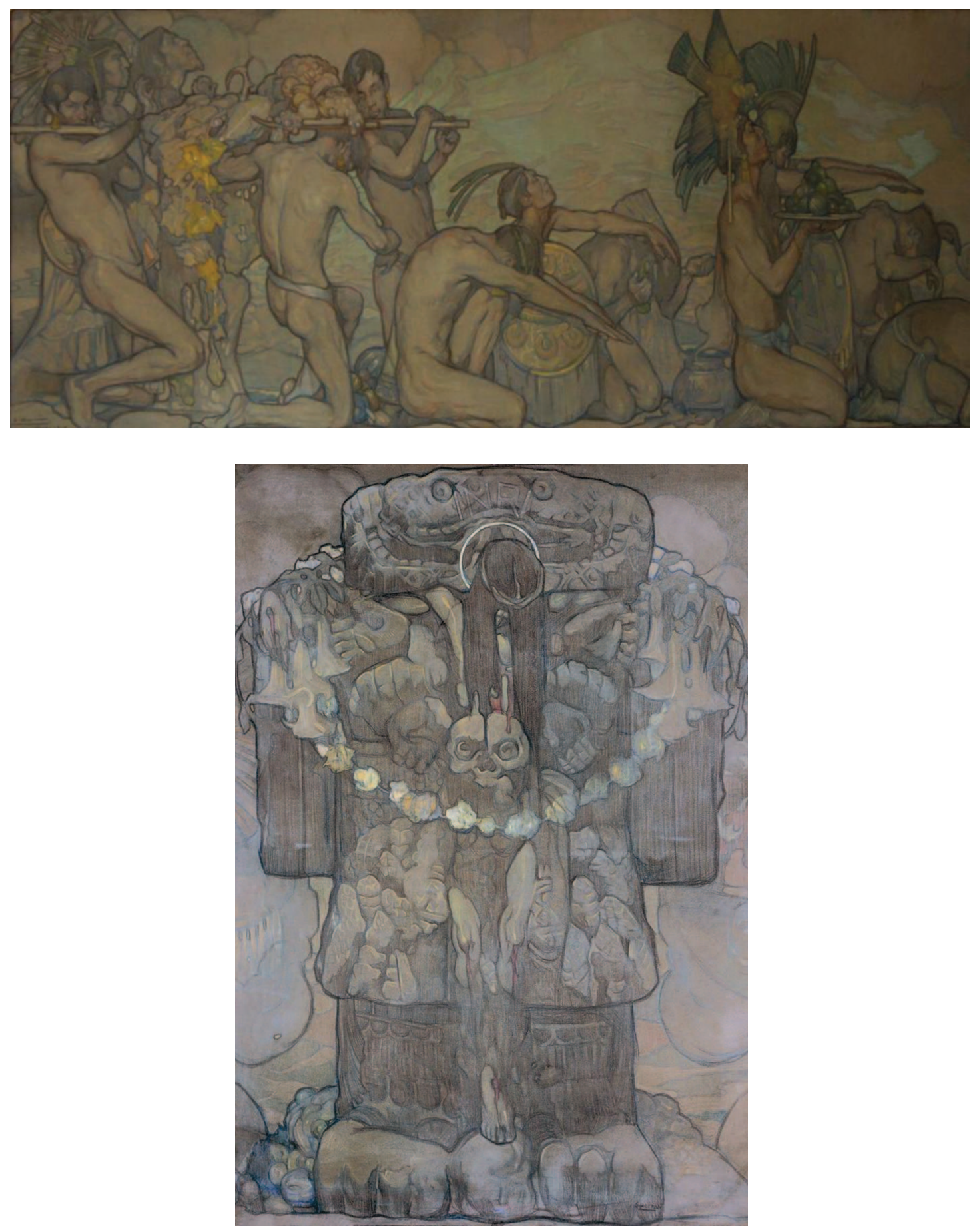


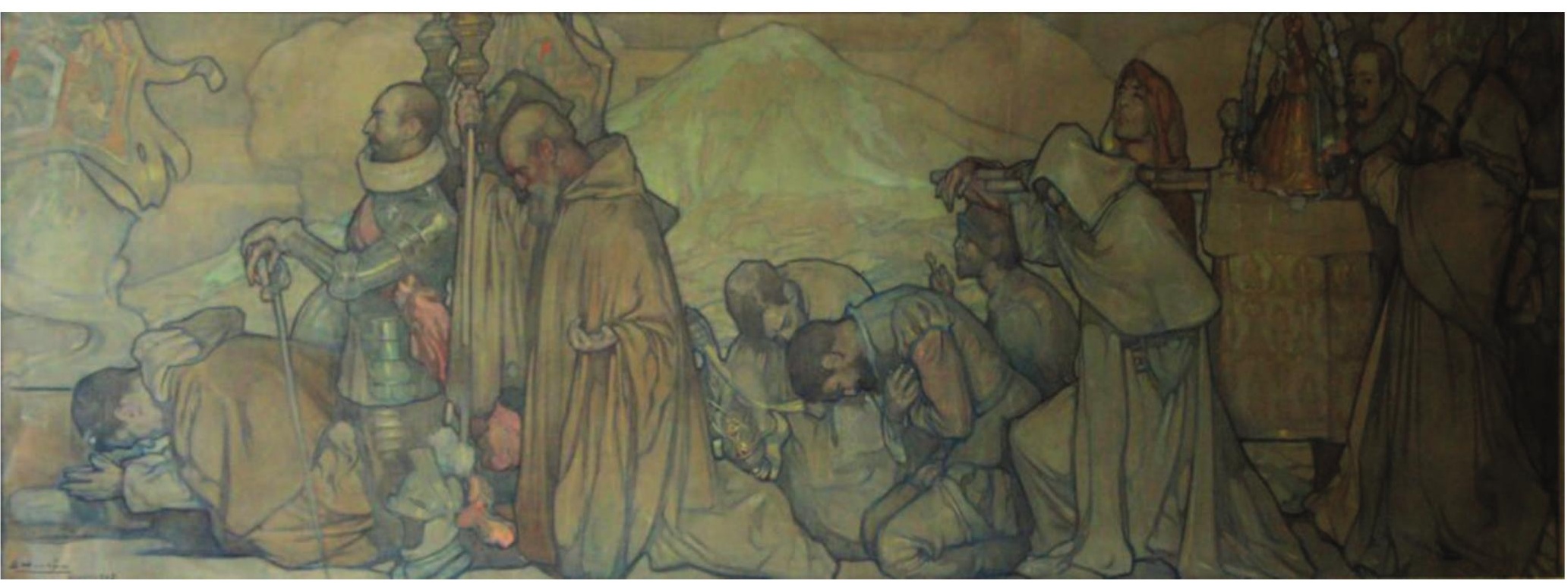

O projeto original de Herrán nunca foi terminado, devido à sua morte prematura no ano de 1918, quando o pintor tinha ainda 31 anos. ${ }^{2}$ Dos três painéis, somente o primeiro, retratando os índios, foi realmente executado em uma tela, tendo os outros dois permanecido como esboços. Ainda assim, o material que permanece é suficiente para nos demonstrar a grandiosidade de seu plano. A fusão em carne da deusa asteca com o filho do deus cristão anuncia a fusão em sangue e espírito de espanhóis e indígenas. A reverência prestada por nativos e conquistadores à divindade unificada concilia, enfim, séculos de desavenças e conflitos.

Ao pintar o tríptico, Herrán reivindica para o México tanto sua ancestralidade espanhola quanto sua ascendência indígena - não por acaso, a composição é batizada de Nuestros Dioses. Mais ainda, o jovem pintor louva o resultado final da fusão entre ambas, saudando-a através dos elementos sagrados de devoção marcantes de cada cenário religioso: à esquerda, oferendas rituais; à direita, uma procissão com o cortejo de uma imagem santa.

$$
* * *
$$

Há entre a carta de Arce y Miranda a Eguiara y Eguren - emblemática da forma como se concebia a questão da "mescla de sangues" entre as elites criollas mexicanas do século XVIII - e o tríptico de Herrán - que não foi escolhido à toa como projeto vencedor para decorar o Teatro Nacional do México - uma mudança fundamental na forma de conceber o processo de mestiçagem. Ele deixa de ser experimentado como um elemento de degradação, "degeneração do sangue", para ser percebido como fator positivo na construção de uma identidade. 
João Gabriel da Silva Ascenso

A proposta central deste trabalho parte do entendimento de que, à mudança de percepção identitária sugerida pelas diferentes concepções apresentadas no tocante à mestiçagem, corresponde uma outra mudança, de ordem semântica, no conceito de raça, tal como ele é utilizado nos ambientes intelectuais mexicanos. No início do século XX, como veremos, a raça chega a tornar-se "cósmica", espiritual, conciliadora, como um fruto da fusão profética entre deuses de diferentes tradições inaugurando um novo homem e uma nova forma de sensibilidade.

\section{Raça cósmica}

Entre 1876 e 1911 o México foi governado pelo general Porfírio Diaz, um longo governo que se encerrou com a sua renúncia em face da chamada $\mathrm{Re}$ volução Mexicana. O corpo intelectual e político mais próximo ao governo foi composto, a partir do fim da década de 1880, pelos chamados “científicos". Reunidos inicialmente em torno do grupo União Liberal, que se empenhou em promover a terceira reeleição de Díaz, os "científicos" tinham propostas de "gestão científica do governo" que se articulavam a partir das doutrinas positivistas, célebres após a atuação na Secretaria de Fazenda de José Ives Limantour, responsável por contornar a grave crise econômica que se abateu sobre o México até 1896 (Cantú, 2008; González, 2000).

Nas ideias defendidas pelo conjunto de tecnocratas, o positivismo se coadunava com os princípios do determinismo biológico e do chamado "darwinismo social". Justo Sierra, um dos mais destacados membros do grupo - subsecretário de Instrução desde 1901, tendo, após a criação da Secretaria de Instrução Pública e Belas Artes, comandado o órgão entre 1905 e 1910 -, postulava que o "sangue empobrecido" do México deveria ser melhorado por meio de "altas doses de sangue forte, fornecido sob a forma da imigração" (Sierra apud Gerstle, 2008: 421).

Ao mesmo tempo que a imigração europeia era defendida e estimulada, no entanto, a modernização econômica atraía uma crescente massa de camponeses, em sua maioria índios e mestiços, para as grandes cidades, evidenciando a necessidade de incorporação desses elementos, vistos como "primitivos", ao Estado nacional. Nesse sentido, reedificou-se uma retórica de valorização da tradição indígena através da reverência ao glorioso passado asteca, degenerado pela experiência colonial, mas que precisava ser reabilitado e agregado ao corpo nacional. Considerável parte da intelectualidade do período passou a defender esse argumento, inclusive o próprio Justo Sierra, inaugurando um discurso de "nacionalismo mestiço" (Gerstle, 2008: 422), que modificava o significado usualmente atribuído ao conceito de raça. 


\section{A redenção cósmica do mestiço}

Esse processo, no entanto, conheceu seu grande impulso a partir dos vários eventos que marcaram a Revolução Mexicana, iniciada em 1910. A imagem de mexicanidade que veio em seu bojo trazia a figura do mestiço como representante da homogeneidade nacional, recuperando aquilo que, no indígena, haveria de contribuir para a formação de um novo tipo de civilização (Moreno, 2000). A própria concepção de povo mudava, passando a remeter, sobretudo, aos setores majoritários da população, notadamente camponeses, índios e rancheros: era em nome desses grupos, e alegadamente para esses grupos, que se fazia a revolução (Montfort, 1999). O mestiço tornava-se o grande herói pátrio, louvado nos discursos revolucionários e, mais tarde, nos discursos oficiais, na literatura, nas artes e em todas as formas de manifestação cultural. Nuestros Dioses, de Saturnino Herrán, se insere completamente dentro desse projeto.

Após a guerra civil, que se estendeu até 1920, iniciou-se a chamada "reconstrução" (1920-1934), período que abrangeu os governos de Álvaro Obregón, de Plutarco Elías Calles e dos três presidentes seguintes, componentes do chamado "Maximato" (designação que faz referência ao próprio Calles, considerado o "chefe máximo da revolução" e a cujos interesses os três estiveram, em maior ou menor grau, subordinados). Nesse momento, o forte nacionalismo que dominava os discursos oficiais se cristalizou justamente em torno desse homem "tipicamente mexicano", o homem mestiço, comprometido com as tradições do folclore de base indígena e, ao mesmo tempo, com os ideais da modernidade europeia, modernidade que, defendia-se, se inaugurava no México a partir da revolução. ${ }^{3}$ Além de legitimar o governo que se propunha revolucionário, esse "nacionalismo mestiço" buscava construir uma unidade nacional, após uma série de conflitos que dividiu o país tanto em termos sociopolíticos e de correntes ideológicas quanto em termos geográficos.

Nesse contexto, um nome ganha especial relevância: o de José Vasconcelos Calderón, célebre filósofo, escritor, educador e homem público mexicano. Nascido em Oaxaca, México, em 1882, e formado em direito em 1907 na Faculdade de Jurisprudência, Vasconcelos teve seu mérito inegavelmente reconhecido na área das letras, da cultura e das políticas educacionais. Em contato, desde antes de se formar, com a juventude intelectual que se opunha aos moldes positivistas dos ideólogos porfiristas, foi membro fundador do Ateneo de la Juventud Mexicana, em 1909. O conhecido corpo de intelectuais - que reuniu escritores como Pedro Henríquez Ureña e Alfonso Reyes Ochoa, o filósofo Antonio Caso e o pintor Diego Rivera - começou como um grupo que pretendia, através de conferências, divulgar as ideias humanistas com as quais seus integrantes pensavam a nacionalidade mexicana, e terminou por se tornar uma das associações intelectuais mais célebres de toda a América Latina. 
Narrar brevemente a vida adulta de Vasconcelos é passar pelos momentos mais célebres da história política mexicana de inícios do século XX. Desde o eclodir da revolução, ele teve uma trajetória marcada pelo apoio a líderes políticos e pelo rompimento com eles, seguido de inúmeras fases de perseguição política e desterro. Vasconcelos foi apoiador do movimento de Francisco I. Madero desde seu princípio e, em meio ao intrincado jogo político que se seguiu ao assassinato deste, chegou a assumir diversos cargos públicos relacionados à educação. Foi o período entre 1921 e 1924, no entanto, que marcou de maneira mais definitiva sua atuação pública, quando assumiu a Secretaria de Educação Pública (SEP), criada na presidência de Álvaro Obregón por meio de um projeto de lei submetido por ele próprio, já que o governo Carranza havia suprimido o antigo ministério. Nesse momento, Vasconcelos empreendeu várias reformas e executou programas de difusão cultural no país, com o intuito de educar a população mexicana e promover as manifestações artísticas.

Vasconcelos desenvolveu uma vasta campanha de alfabetização nas áreas rurais do país organizando os corpos de "maestros misioneros", criou escolas e bibliotecas e imprimiu e distribuiu em massa as obras clássicas gregas e latinas. Além disso, inúmeros festivais de música e danças populares foram promovidos, assim como foi incentivada uma produção literária que valorizava o elemento tradicional em diálogo com os ideais de modernidade que vinham com a revolução. Afora isso, o muralismo, estilo de pintura extremamente difundido nas primeiras décadas do século XX, ganhou um fôlego extraordinário, retratando temas como a vida dos camponeses, os costumes indígenas e a revolução vitoriosa.

Apesar do sucesso de sua atuação no ministério, a relação desconfiada e, por vezes, conflituosa de Vasconcelos com Obregón o levou a renunciar a seu cargo em 1924, sob a alegação oficial de que se preparava para sua candidatura ao governo do estado de Oaxaca. Um pedido de renúncia já havia sido apresentado (e retirado, logo depois), meses antes, em protesto contra o assassinato do senador Field Jurado, o que ajudou a desgastar uma relação que já vinha sofrendo com a crescente dificuldade de Vasconcelos em implementar suas propostas na SEP. Após esse momento, Vasconcelos se envolveu em uma série de eventos que incluíram o fracasso de sua campanha em Oaxaca e, posteriormente, na disputa pela presidência do país, uma convocação popular fracassada à luta armada (o chamado Plano de Guaymas), além de sucessivos exílios que se seguiram até o ano de $1940 .^{4}$

A obra de Vasconcelos se constituiu como um grande apelo à construção de uma nação mexicana forte, assentada nas bases da educação e de uma cultura nacionalista que levasse a uma unidade, a uma homogeneidade da população, fundada em elevados valores morais e espirituais. Data do ano de 1925 a publica- 
ção de seu famoso ensaio La raza cósmica: misión de la raza iberoamericana, na cidade de Barcelona, Espanha. Nele, através de uma reinvenção da concepção oitocentista de raça, o autor propunha uma nova identidade para o povo mexicano, pautada não no rigor científico das doutrinas raciais clássicas, mas na transcendência metafísica da união espiritual de tipos humanos diferentes, identidade essa que redefinia as expectativas relacionadas ao papel que esse povo - e, mais genericamente, o povo latino-americano - ocuparia na história.

O cerne da hipótese de Vasconcelos, que ele definia como "versão dos Impérios étnicos", partia da constatação de que houve na história do mundo uma sucessão de impérios que atingiram seu apogeu e, logo depois, decaíram, dando lugar a outros. Cada um desses impérios teria sido marcado pela ascensão de uma raça específica:

Tenemos entonces las cuatro etapas y los cuatro troncos: el negro, el indio, el mogol y el blanco. Este último, después de organizarse en Europa, se ha convertido en invasor del mundo, y se ha creído llamado a predominar lo mismo que lo creyeron las razas anteriores, cada una en la época de su poderío. Es claro que el predominio del blanco será también temporal, pero su misión es diferente de la de sus predecesores; su misión es servir de puente. El blanco ha puesto al mundo en situación de que todos los tipos y todas las culturas puedan fundirse. La civilización conquistada por los blancos, organizada por nuestra época, ha puesto las bases materiales y morales para la unión de todos los hombres en una quinta raza universal, fruto de las anteriores y superación de todo lo pasado. (Vasconcelos, 2010: 5)

Essa quinta raça, que Vasconcelos chama de "raça cósmica", surgiria a partir do processo historicamente conhecido como mestiçagem, caracterizado pela fusão entre as quatro raças que a antecederam: a negra africana, a vermelha americana-ou índia -, a amarela asiática - ou mongol-e a branca europeia. Esse movimento de fusão teria se dado, historicamente, a partir da ação de "ponte" da raça branca, ao invadir e conquistar vastas regiões do mundo. Mas é necessário fazer uma advertência: o processo de mestiçagem, para Vasconcelos, longe de ser puramente biológico, é, sobretudo, um processo espiritual. O que está se misturando não é apenas o sangue de elementos raciais diferentes, mas o seu espírito, seus atributos transcendentais.

Cada raça teria qualidades positivas a agregar à nova raça em formação, e, ao mesmo tempo, teria defeitos que seriam gradativamente extintos graças ao processo de fusão racial. Esse processo, contudo, não poderia se dar em qualquer lugar, senão em um continente bem específico: a América Latina. Local histori- 
camente afeito à mestiçagem e cosmopolita por natureza, a ele caberia a missão de servir de berço para o nascimento de uma nova humanidade. Nesse continente, a raça branca havia se fundido com a raça vermelha dando origem a um novo tipo humano, que também se misturou, com o passar do tempo, com os negros e os amarelos.

No entanto, se, de acordo com sua argumentação inicial, a raça branca europeia seria a responsável por incorporar os elementos vários na formação de uma nova raça, Vasconcelos faz uma ressalva: "no fue Europa en conjunto la encargada de iniciar la reincorporación del mundo rojo a las modalidades de la cultura preuniversal, representada, desde hace siglos, por el blanco" (com a categoria de "cultura pré-universal" Vasconcelos define o estágio anterior ao da universalização que marcaria a formação da raça cósmica). "La misión transcendental correspondió a las dos más audaces ramas de la familia europea: a los tipos humanos más fuertes y más disímiles: el español y el inglés" (Idem: 5-6). Mais à frente, para incluir na descrição do processo de conquista da América (origem da fusão racial sistemática), de um lado, portugueses, e do outro, holandeses, Vasconcelos define esses dois ramos da família europeia como "latinos" e "saxões".

O que se segue, então, é uma descrição do que o autor chama de "luta secular entre latinos e saxões", da qual o povo americano seria herdeiro até aquele momento. Cada um desses povos teria um estilo de civilização peculiar e uma forma diferente de lidar com o "elemento estranho" - as outras raças - durante o processo de colonização. Essas diferenças seriam, justamente, o que garantiria a vitória dos latinos na luta contra os saxões, a partir da qual surgiria a raça cósmica.

Tal raça, segundo Vasconcelos, nunca poderia surgir a partir da ação dos "saxões do Norte", termo com o qual classifica os estadunidenses. Por mais que, ao longo dos últimos séculos, a porção latina da América se tivesse mostrado inferior, desunida, condenada ao fracasso - e que a explicação tradicional desse atraso o relacionasse à mestiçagem, que, unindo tipos humanos antagônicos, teria gerado um homem defeituoso -, Vasconcelos defende que seria justamente essa composição mestiça que faria com que os latinos atingissem um patamar mais elevado do que o dos saxões, ainda que esse processo de fusão racial levasse tempo para "plasmar", para mostrar seu potencial. Diz ele:

Reconozcamos que fue una desgracia no haber procedido con la cohesión que demostraron los del Norte; la raza prodigiosa, a la que solemos llenar de improperios, sólo porque nos ha ganado cada partida de la lucha secular. [...] Ellos no tienen en la mente el lastre ciceroniano de la fraseología, ni en la sangre los instintos contradictorios de la mezcla de razas disímiles; pero co- 


\section{A redenção cósmica do mestiço}

metieron el pecado de destruir esas razas, en tanto que nosotros las asimilamos, y esto nos da derechos nuevos y esperanzas de una misión sin precedentes en la Historia.

De aquí que los tropiezos adversos no nos inclinen a claudicar; vagamente sentimos que han de servirnos para descubrir nuestra ruta. Precisamente, en las diferencias encontramos el camino; si no más imitamos, perdemos; si descubrimos, si creamos, triunfaremos. La ventaja de nuestra tradición es que posee mayor facilidad de simpatía con los extraños. Esto implica que nuestra civilización, con todos sus defectos, puede ser la elegida para asimilar y convertir a un nuevo tipo a todos los hombres. En ella se prepara de esta suerte la trama, el múltiple y rico plasma de la Humanidad futura. (Idem: 13-14, grifos da edição)

Tal humanidade futura haveria de se consumar justamente a partir da mistura biológica e espiritual que se processava na América Latina, a partir da ação da raça branca - cujas contribuições fundamentais para a humanidade, além de sua ação de ponte, seriam as conquistas científicas e o domínio da natureza física. Tais conquistas, no entanto, fundadas no desenvolvimento da razão, não caracterizariam o estágio mais elevado que a sociedade poderia atingir. Esse estágio seria marcado pela chamada "lei do gosto", sendo pautado por motivos de ordem espiritual e estética.

Esta proposição, apresentada no ensaio "Nueva ley de los Tres Estados"5 $\mathrm{e}$ repetida em La raza cósmica, parte da compreensão de que os homens se vão, pouco a pouco, libertando do domínio da necessidade (marcante do estado material, ou guerreiro) e do pragmatismo racional (típico do estado intelectual, ou político), para se submeter às normas superiores do sentimento, da fantasia, do gosto estético, num movimento que, por vezes, se confunde com a própria promessa de realização cristã:

Fesucristo [es] el autor del mayor movimiento de la Historia; el que anunció el amor de todos los hombres. Este amor será uno de los dogmas fundamentales de la quinta raza, que ha de producirse en América. El cristianismo liberta y engendra vida, porque contiene revelación universal, no nacional [...]. (Idem: 30)

Dessa forma, no porvir da humanidade futura, um terceiro estado se consumaria, através da mestiçagem e da formação da raça cósmica: esse é o fim do plano que Vasconcelos busca enxergar na história. 
João Gabriel da Silva Ascenso

\section{A redenção cósmica do mestiço e a inversão semântica do conceito de raça}

¿Qué importa que el materialismo spenceriano nos tuviese condenados, si hoy resulta que podemos juzgarnos como una especie de reserva de la Humanidad, como una promesa de un futuro que sobrepujara a todo tiempo anterior?

(Vasconcelos, 2010: 32)

Com essas palavras, Vasconcelos anuncia a redenção do homem mestiço da América Latina - condenado pela ciência oitocentista, mas absolvido "cosmicamente" no plano histórico de construção de uma humanidade futura. Por ser o elo entre os quatro impérios étnicos e a raça cósmica, o mestiço aparece dotado de qualidades superiores, algumas ainda por despertar. Isso porque cada uma das quatro grandes raças (negra, vermelha, amarela e branca) teria elementos positivos que seriam compartilhados no processo de fusão racial, ao passo que os negativos seriam deixados de lado. Como esse processo se consumaria no "terceiro estado" humano, o período de governo do gosto estético, a própria vontade livre cuidaria para que esses elementos negativos sumissem.

De todo modo, ainda que Vasconcelos pareça propor que todas as raças contribuiriam de igual maneira na construção do homem cósmico do futuro, é patente que seu texto se encontra carregado de várias das concepções hierarquizadoras de raças que, objetivamente, o autor se propõe a atacar, e que a raça branca ainda apresenta traços de superioridade em relação às outras três raças que precedem a raça cósmica. Mesmo quando Vasconcelos procura afirmar os elementos positivos dos negros, índios e orientais, aparece nítida uma conceituação do branco como superior, mais próximo à raça cósmica - ainda que isso não justifique ações de violência para com as outras raças: "Quizás entre todos los caracteres de la quinta raza predominen los caracteres del blanco, pero tal supremacía debe ser fruto de elección libre del gusto y, no resultado de la violencia o de la presión económica" (Idem: 21).

É notório que Vasconcelos, em certa medida, não escapa aos preconceitos que são próprios ao discurso racial de seu tempo. Ele age no sentido de afirmar uma identidade fora dos padrões europeus, mas, ainda assim, a identidade mestiça proposta por ele reivindica-se, em grande parte - algumas vezes em sua maior parte-, como herdeira da Europa (sobretudo dos latinos, dos espanhóis), e a moral final que deve guiar a raça cósmica é, sem dúvida, a moral cristã.

De todo modo, a figura do mestiço aparece reinventada na retórica vasconceliana, e essa reinvenção redentora acaba por redimir a própria América Latina, palco de sua missão. Dois países ocupam papel fundamental na previsão que Vasconcelos faz para o futuro latino-americano: Brasile Argentina. Se isso já é perceptível na primeira parte de La raza cósmica, "El mestizaje", na segunda parte do ensaio, "Notas de viaje", fica evidente. Não por acaso, tais notas se referem a 


\section{A redenção cósmica do mestiço}

viagens feitas a esses dois países. O Brasil é descrito como o país do futuro, o cenário no qual se desenvolverá a raça cósmica; a Argentina, por sua vez, é encarada como a capital da América de fala espanhola, herdeira das virtudes castelhanas. No Sul, portanto, mais especificamente nos trópicos americanos, estaria o futuro da humanidade.

Surpreende, à primeira vista, o fato de não ser o México o alegado país onde a raça cósmica haveria de anunciar-se. Ao contrário, nas "Notas de viaje", o país natal de Vasconcelos aparece como fracassado (chegando mesmo a ser descrito como selvagem!) em comparação ao Brasil e à Argentina. É possível que esse posicionamento acerca do México reflita as dificuldades que, em sua própria vivência pessoal, Vasconcelos encontrou para a realização de seus sonhos de construção de uma nova realidade mexicana, ain da que tal especulação se mostre pouco produtiva para o trabalho aqui desenvolvido. De todo modo, é evidente que a ênfase na mestiçagem, sobretudo em relação ao elemento indígena, na construção do futuro de progresso da América Latina age no sentido de legitimar a própria população mestiça mexicana. Nesse sentido, ainda que se revelasse fracassado e selvagem, o México seria - junto à América Latina, como um todo redimido através do mestiço.

Os usos políticos desse discurso parecem óbvios, e se manifestam sobretudo na legitimação das nações latino-americanas e no combate ao imperialismo estadunidense. De fato, o próprio anúncio da vitória dos latinos sobre os saxões traz consigo a ideia de que o apogeu dos Estados Unidos não duraria para sempre, pois suas bases são frágeis: "Los días de los blancos puros, los vencedores de hoy, están tan contados como lo estuvieron los de sus antecesores" (Idem: 13). Mais do que isso: "Acabarán de formar los yanquis el último gran imperio de una sola raza: el imperio final del poderío blanco" (Idem: 17).

Segundo Vasconcelos, todo grande império de "raça pura", ao longo da história, tentou se afirmar a partir do extermínio das outras raças, e essa parecia ser a intenção do imperialismo norte-americano. O grande discurso que o legitimava seria justamente $o$ argumento racial em seus moldes científicos oitocentistas, os quais Vasconcelos procura combater em todo o seu ensaio:

Todo imperialismo necesita de una filosofía que lo justifique [...]. Los británicos predican la selección natural, con la consecuencia tácita de que el reino del mundo corresponde por derecho natural y divino al dolicocéfalo de las Islas y sus descendientes. [...] Cada raza que se levanta necesita constituir su propia filosofía, el deus ex machina de su éxito. Nosotros nos hemos educado bajo la influencia humillante de una filosofía ideada por nuestros enemigos, si se quiere de una manera sincera, pero con el propósito de exaltar sus propios fi- 
João Gabriel da Silva Ascenso

nes y anular los nuestros. De esta suerte nosotros mismos hemos llegado a creer en la inferioridad del mestizo, en la irredención del indio, en la condenación del negro, en la decadencia irreparable del oriental. La rebelión de las armas no fue seguida de la rebelión de las conciencias. Nos rebelamos contra el poder político de España, y no advertimos que, junto con España, caímos en la dominación económica y moral de la raza que ha sido señora del mundo desde que terminó la grandeza de España [...]; pero ahora que se inicia una nueva fase de la Historia, se hace necesario reconstituir nuestra ideología y organizar conforme a una nueva doctrina étnica toda nuestra vida continental. Comencemos entonces haciendo vida propia y ciencia propia. Si no se liberta primero el espíritu, jamás lograremos redimir la materia. (Idem: 29-30)

É, em grande parte, no sentido de combater as concepções científicas e filosóficas que legitimam a dominação imperialista que Vasconcelos escreve sua $R a z a$ cósmica. $\mathrm{O}$ autor se posiciona claramente contra o cientificismo, propondo em seu lugar uma doutrina metafísica ("cósmica"); ao invés de falar de eugenia biológica, fala de "eugenia do espírito", e relaciona o estágio mais elevado da humanidade a uma concepção não racional, mas estética e espiritual. Com isso, propõe o que chamo de uma "redenção cósmica" do mestiço, através da qual a significação da mestiçagem se altera: de fator degenerativo ela passa a ser reivindicada como elemento forjador de uma identidade, e com uma função histórica muito especial. ${ }^{6}$

O processo de redenção se realiza através de uma verdadeira inversão semântica no próprio conceito de raça, com o fim político de afirmar a identidade mestiça na América Latina e, através de uma lógica metonímica inversa, legitimar a nação mestiça mexicana. Essa inversão semântica se realiza em três direções principais:

\section{- Primeira direção: "do plural para o singular" (ou "da exclusão para a inclusão")}

La quinta raza no excluye, acapara vida; por eso la exclusión [...] de cualquier [...] tipo humano equivaldría a una mutilación anticipada, más funesta aun que un corte posterior. (Vasconcelos, 2010: 22)

Desde sua gênese o discurso racial foi utilizado no sentido de identificar e agrupar "tipos humanos" diferentes, prática que no século XIX ganha a legitimação de uma argumentação cientificista. Evidentemente, esse esforço de "organizar" a diversidade humana a partir da designação racial não ocorre de forma 
"neutra", de modo que qualidades morais e intelectuais são atribuídas às diversas raças humanas identificadas no mundo. Dessa forma, o conceito de raça serve para afirmar a superioridade de certos grupos em detrimento de outros.

Isso ocorre porque ele opera engendrando "oposições assimétricas", que se manifestam em expressões binárias do tipo "raça superior/raça inferior", as quais se relacionam a oposições recorrentes como "pureza/impureza" e "civilização/barbárie". Em todas elas, os pares conceituais se revelam assimetricamente desiguais, e essa assimetria é utilizada politicamente em um sentido de dominação: os grupos que se afirmam como superiores (notadamente a "raça branca" europeia) legitimam a dominação, a coerção e, por vezes, mesmo o extermínio das outras raças através de um discurso que estabelece uma distância intransponível entre elas.

Combatendo essa perspectiva, Vasconcelos defende uma nova concepção de raça. Longe de legitimar a segregação e a dominação, propõe a união fraterna de todos os tipos humanos que, fundindo-se, garantiriam a unidade transcendental e universal da humanidade futura. Ainda que a pluralidade de raças seja afirmada como condição passada e presente, a reivindicação da raça em si não serve para legitimar a exclusão, pois que a única finalidade de existirem grupos raciais distintos seria a sua fusão na formação de um único tipo humano superior, a assimilação mútua de todas as características positivas, o que levaria à construção de uma única raça, a raça cósmica, em um futuro anunciado. É uma proposta, portanto, de inclusão.

O conceito de raça, nesse sentido, sofre uma inversão semântica na direção do plural (várias raças) para o singular (uma só raça: a raça síntese). Essa qualidade singular que o conceito adquire remete a um momento histórico específico: o futuro. Isso nos leva à segunda direção em que a inversão semântica se apresenta.

\section{- Segunda direção: "do passado para o futuro"}

El camino que hemos iniciado nosotros [la raza iberoamericana] es mucho más atrevido, rompe los prejuicios antiguos, y casi no se explicaría, si no se fundase en una suerte de clamor que llega de una lejanía remota, que no es la del pasado, sino la misteriosa lejanía de donde vienen los presagios del porvenir. (Vasconcelos, 2010: 17)

O pesquisador italiano Guido Barbujani, em sua elucidativa obra $A$ invenção das raças, apresenta duas possíveis origens etimológicas para o conceito de raça: ou ele derivaria da palavra raiz, em sua forma italiana, tendo passado depois para o francês e o inglês, ou do termo árabe ras, que pode significar cabeça ou indicar estirpe, descendência. 
Quer a versão correta seja a que remete ao termo italiano ou ao árabe, é notório que a ideia de raça alude, historicamente, a uma noção de origem, de procedência (qualidade presente tanto no campo semântico de "raiz" quanto no de “estirpe”). Definir a raça de alguém significava originariamente, portanto, definir a procedência desse indivíduo, o tronco familiar ao qual ele estava ligado. Essa concepção se manteve predominante quando da disseminação do conceito pelo cenário intelectual europeu e serviu para classificar a diversidade humana em grupos de proveniências distintas - as quais, evidentemente, foram relacionadas a traços físicos, distinções biológicas, capacidades maiores ou menores de raciocínio e valores morais mais ou menos desenvolvidos.

O que Vasconcelos faz é descolar a idéia de raça da experiência de um passado, através da criação de um neologismo com conteúdo de prognóstico: raça cósmica. A raça cósmica realiza-se, sobretudo, no futuro, na expectativa. É o seu anúncio que dá sentido ao discurso racial no presente, pois que a razão da existência das raças é a sua prometida fusão. O discurso racial se justifica, portanto, não pela sua referência a um início, mas pelo anúncio de um novo fim.

\section{- Terceira direção: "de fora para dentro"}

Nosotros nos hemos educado bajo la influencia humillante de una filosofía ideada por nuestros enemigos [...] con el propósito de exaltar sus propios fines y anular los nuestros. [...] Ahora que se inicia una nueva fase de la Historia, se hace necesario reconstituir nuestra ideología y organizar conforme a una nueva doctrina étnica toda nuestra vida continental. Comencemos entonces haciendo vida propia y ciencia propia.

(Vasconcelos, 2010: 29-30)

Finalmente, a terceira direção remete ao próprio lugar reivindicado pelo agente do discurso racial. Se o conceito de raça ao longo dos séculos foi utilizado para indicar posições assimetricamente desiguais entre os tipos humanos, legitimando ações de dominação e violência, a estruturação de tal assimetria no discurso racial serviu a determinados grupos que se beneficiaram desse discurso, que reivindicaram para si o status de superior, em oposição ao genérico "outro". Historicamente, o europeu - de pretensa raça branca -, ou, posteriormente, o estadunidense, representaram esses grupos, ao passo que o "colonizado" (ou aquele que sofria o imperialismo) interagiu de diferentes modos com a mensagem racial, ressignificando-a e, em certa medida, legitimando e reproduzindo-a, tornando-se também agente de um discurso de dominação. 


\section{A redenção cósmica do mestiço}

É evidente que não podemos entender a legitimação de um discurso de dominação, por parte de quem a sofre, como a vitória de uma cultura sobre a outra, ou de certas categorias exógenas contra categorias endógenas. Inúmeros estudos já evidenciaram que se trata, de fato, de processos de negociação. No entanto, é inegável que o "lugar" afirmado majoritariamente pelos agentes do discurso racial na América Latina, originariamente, era o da dominação externa (ainda que eles não necessariamente pertencessem a este lugar).

Vasconcelos, por outro lado, recusa-se a reproduzir essa mensagem. Em sua obra, afirmar a raça passa a significar afirmar qualidades positivas de grupos raciais historicamente considerados inferiores. A raça deixa de ser concebida a partir de um lugar de fala externo, que legitima uma autoridade de dominação, e passa a ser reivindicada por um lugar de fala interno, como símbolo de autonomia e de capacidade. Na obra de Vasconcelos, a raça representa a possibilidade de construção de um futuro de progresso e unidade nacional, através da figura positivada do mestiço que encarna valores morais e espirituais. Invertendo-se a carga semântica do conceito, toda a força direcionada para condenar a raça passa a ser direcionada para louvá-la.

Se é verdade, como argumenta Claude Fell, que "la 'raza' de Vasconcelos, como el 'hombre' de Rodó, no pasa de ser una entidad abstracta, futura, utópica" (Fell, 1989: 657), parece-me evidente que a sua proposta filosófica e estética apresenta um conteúdo político bem nítido. $\mathrm{O}$ universalismo que Vasconcelos identifica como o caminho a ser percorrido, em primeiro lugar pela América Latina e, posteriormente, pelo mundo todo, é um universalismo que dialoga com a própria maneira como a expectativa de um futuro mexicano é vivenciada pela geração do autor, preocupada em construir uma unidade nacional depois de dez anos de guerra civil, em meio a uma população heterogênea e constantemente ameaçada pelo expansionismo estadunidense.

Se, por um lado, Vasconcelos não escapa - e nem pretende escapar! - às heranças culturais europeias que, ao longo dos séculos, serviram à legitimação da dominação colonial, por outro parece pretender que ela chegará ao fim no futuro, quando a harmonização conduzida pelo "espírito" levaria a uma homogeneidade que ressignificaria e fortaleceria a identidade nacional mexicana - inextrincável a uma identidade latino-americana e, mais do que isso, a uma identidade humana universal. É nesse sentido que podemos afirmar que, tanto em sua atuação na SEP como em sua produção ensaística, "Vasconcelos se cuenta entre los primeros que, en Latinoamérica, luchan y actúan para instaurar una cultura a la vez nacional, continental y popular" (Fell, 1989: 14). 
O instrumento através do qual Vasconcelos percorre esse trajeto, em seu célebre ensaio de 1925, é o conceito de raça. É a nova carga semântica que lhe é atribuída que permite que as oposições assimétricas entre raças diferentes sejam superadas, pois o próprio conceito passa a remeter, necessariamente, ao fim da oposição e à união absoluta de todas as raças, dirigindo-se a partir de então ao porvir. Em outras palavras, só faz sentido falar em raça porque a "raça cósmica" se anuncia, e porque seu anúncio, vivenciado no presente, é um elemento de enorme impacto na construção política de uma nação herdeira de Jesus, de Coatlicue, e de muitos outros deuses.

\section{Notas}

1. Há referência à carta de Andrés Arce y Miranda nos trabalhos de Morales (1983), Katzew (1997) e Estrada (2006).

2. Para mais informações sobre a vida e a obra de Saturnino Herrán, cf. Barnitz (2001).

3. Deve-se destacar que o papel reservado ao indígena, nesse momento, era o de portador de uma herança cultural rica, mas que deveria ser integrada à estrutura do Estado nacional. Os índios que se recusassem a abandonar suas formas tradicionais de organização e propriedade continuariam a ser encarados como um problema a ser superado.

4. As informações biográficas a respeito de Vasconcelos podem ser encontradas na excelente cronologia realizada por Claude Fell em sua edição crítica de Ulises criollo (2000: 545-572).

5. Uma evidente referência à "lei dos três estados" de Comte, a qual Vasconcelos subverte por desqualificar o puro conhecimento científico em nome de uma ordem metafísica, espiritual.

6. Não podemos esquecer, de todo modo, que a garantia de que essa "redenção cósmica" será efetiva se encontra na concep- ção, de Vasconcelos, da mestiçagem como um processo de homogeneização racial, produtor, portanto, de uma unidade. Nesse entendimento, os grupos raciais asseguram seu valor a partir de sua junção num tipo superior (cósmico), marcado pela estabilidade. Trata-se, evidentemente, de uma visão de mestiçagem diferente das atuais discussões sobre transculturação e hibridismo (com Néstor García Canclini, por exemplo), que concebem o mestiço como um entrecruzamento de referências étnicas e culturais, intrincadas em processos políticos e econômicos e, portanto, em constante movimento, choque, instabilidade. Um campo em que esta discussão apresenta particular desenvolvimento é o caso dos "chicanos", descendentes de mexicanos residentes nos Estados Unidos. O já icônico trabalho de Gloria Anzaldúa, Borderlands/La frontera: the new mestiza (1987), por exemplo, parte da ideia de fronteira (física, cultural, social, linguística...) que marca os chicanos para ampliar a discussão até as fronteiras de gênero, classe, orientação sexual e religiosidade. Estar no entre-lugar das fronteiras, segundo Anzaldúa, engloba a possibilidade de transgredi-las, desafiando o binarismo do racionalismo ocidental. 


\section{A redenção cósmica do mestiço}

Referências bibliográficas

ANZALDÚA, Gloria. Borderlands/La frontera: the new mestiza. São Francisco: Aunt Lute, 1987.

BARBUJANI, Guido. $A$ invenção das raças. São Paulo: Contexto, 2009.

BARNITZ, Jacqueline. Twentieth-Century art of Latin America. Austin: University of Texas Press, 2001. Disponível parcialmente em "Google Livros": <http://books.google. com.br/bkshp?hl=pt-BR\&tab =wp $>$. Acesso em: 24/05/2013.

CANTÚ, Gloria M. Delgado de. Historia de México: legado histórico y pasado reciente. México: Pearson Educación, 2008.

CARRERA, Magali. Imagining identity in New Spain: race, lineage and the colonial body in portraiture and casta paintings. Austin: University of Texas Press, 2003.

ESTRADA, Dorothy Tanck. En búsqueda de México y los mexicanos en el siglo XVIII. Seminario de Historia Intelectual de América Latina, 2006. Disponível em: $<$ http://shial.colmex.mx/textos/DorothyT anck.pdf>. Acesso em: 24/05/2013.

FELL, Claude. Fosé Vasconcelos: los años del águila (1920-1925). Educación, cultura e iberoamericanismo en el México postrevolucionario. México: UNAM, 1989.

Cronología. In: VASCONCELOS, José. Ulises criollo. Edição crítica coordenada por Claude Fell. Madri; Barcelona; Havana; Lisboa; Paris; México; Buenos Aires; São Paulo; Lima; Guatemala; San José: ALLCA XX, 2000.

GERSTLE, Gary. Raça e nação nos Estados Unidos, México e Cuba, 1880-1940. In: PAMPLONA, Marco A.; DOYLE, Don H. (orgs.). Nacionalismo no Novo Mundo. Rio de Janeiro: Record, 2008.
GONZÁLEZ, Luis González y. El liberalismo triunfante. In: VILLEGAS, Daniel Cosío. Historia general de México. México: El Colegio de México, 2000.

KATZEW, Ilona. Casta painting: identity and social stratification in colonial Mexico. In: Laberinto: an electronic journal of early modern Hispanic literatures and culture, Glendale (Arizona), vol. 1, n. 1-2, 1997. Disponível em: < http://www.gc.maricopa. edu/laberinto/fall1997/casta1997.htm $>$. Acesso em: 24/05/ 2013.

KOSELLECK, Reinhart. Futuro passado: contribuição à semântica dos tempos históricos. Rio de Janeiro: Contraponto/PUC-Rio, 2006.

MONTFORT, Ricardo Pérez. Un nacionalismo sin nación aparente (la fabricación de lo "típico" mexicano 1920-1950). Política y Cultura, Universidad Autónoma Metropolitana, Xochimilco, México, n. 12, 1999.

MORALES, Efraín Castro. Los cuadros de castas de la Nueva España. Fahrbuch für Geschichte von Staat, Wirtschaft, und Gesellschaft Lateinamerikas. Colônia/Alemanha: Böehlau Verlag, n. 20, 1983. Disponível em: <http://americas.sas.ac. uk/publications/docs/genero_segunda4_C astro.pdf> . Acesso em: 24/05/2013.

MORENO, Javier Rico. Pasado y futuro en la historiografía de la Revolución Mexicana. México: UAM-A/Conaculta-INAH, 2000.

VASCONCELOS, José. La raza cósmica. México: Editorial Porrúa, 2010.

La otra raza cósmica. Oaxaca de Juárez: Almadía, 2010.

Nueva ley de los tres estados. In: Ideario de acción. Lima: Ediciones Actual, 1924 apud —. The cosmic race: a bilingual edition. Baltimore: The Johns Hop- 
João Gabriel da Silva Ascenso

kins University Press, 1997. Disponível parcialmente em "Google Livros": $<$ http://books.google.com.br $>$. Acesso em: 11/06/2013.

\section{Iconografia}

Casta. Autor anônimo. Número de catálogo PI/0869. Museo Nacional del Virreinato.
CONACULTA.-INAH.-MEX, "Reproducción Autorizada por el Instituto Nacional de Antropología e Historia”.

Nuestros Dioses (tríptico). Autor: Saturnino Herrán. Museo de Aguascalientes. CONACULTA.-INBA.-MEX, "Reproducción Autorizada por el Instituto Nacional de Bellas Artes y Literatura, 2013”.

\section{Resumo}

Partindo da constatação de que, no início do século XX, operou-se uma modificação na forma de se conceber a mestiçagem no México, o presente artigo pretende investigar como essa modificação se relacionou ao conceito de raça. Analisa-se especificamente o ensaio La raza cósmica (1925), de José Vasconcelos, que defende que na América Latina se formaria uma nova raça, em um processo de mestiçagem sobretudo espiritual. Através de uma inversão semântica no conceito de raça, o autor apresenta uma nova proposta de identidade latino-americana, com o fim político de legitimar as nações do continente e de se opor ao imperialismo estadunidense.

Palavras-chave: raça cósmica; mestiçagem; México; América Latina; José Vasconcelos.

\section{Abstract \\ Assuming that at the beginning of $20^{\text {th }}$ century there has been a change in the way of conceiving miscegenation in Mexico, this article intends to investigate how this change was related to the concept of race. I analyze the essay La raza cósmica (1925), by José Vasconcelos, who sustained that in Latin America a new race would be formed, in a spiritual miscegenation. Through a semantic inversion of the concept of race, the author presents a new proposal of Latin-American identity, with the political purpose of legitimating the nations of the continent and confronting U.S. imperialism.} Keywords: cosmic race; miscegenation; Mexico; Latin America; José Vasconcelos. 


\begin{abstract}
Résumé
À partir de la constatation qu'au début du XXème siècle la manière de concevoir le métissage a changé au Mexique, cet article veut étudier comment cette modification était liée au concept de race. L'auteur analyse l'essai La raza cósmica (1925), de José Vasconcelos, qui défend l'idée qu'une nouvelle race se formerait en Amérique Latine en conséquence d'un métissage surtout spirituel. Par une inversion sémantique du concept de race, l'auteur présente une nouvelle proposition d'identité latino-américaine, dans le but politique de légitimer les nations du continent et de faire face à l'impérialisme des États Unis.

Mots-clés: race cosmique; métissage; Mexique; Amérique Latine; José Vasconcelos.
\end{abstract}

